\title{
Erratum: "VUV-Luminescence and Excitation Spectra of the Heavy Trivalent Rare-Earth Ions in Fluoride Matrices" [Physics of the Solid State 47, 1416 (2005)]
}

M. Kirm, V. N. Makhov, M. True, S. Vielhauer, and G. Zimmerer

The correct version of Fig. 2 is given below.
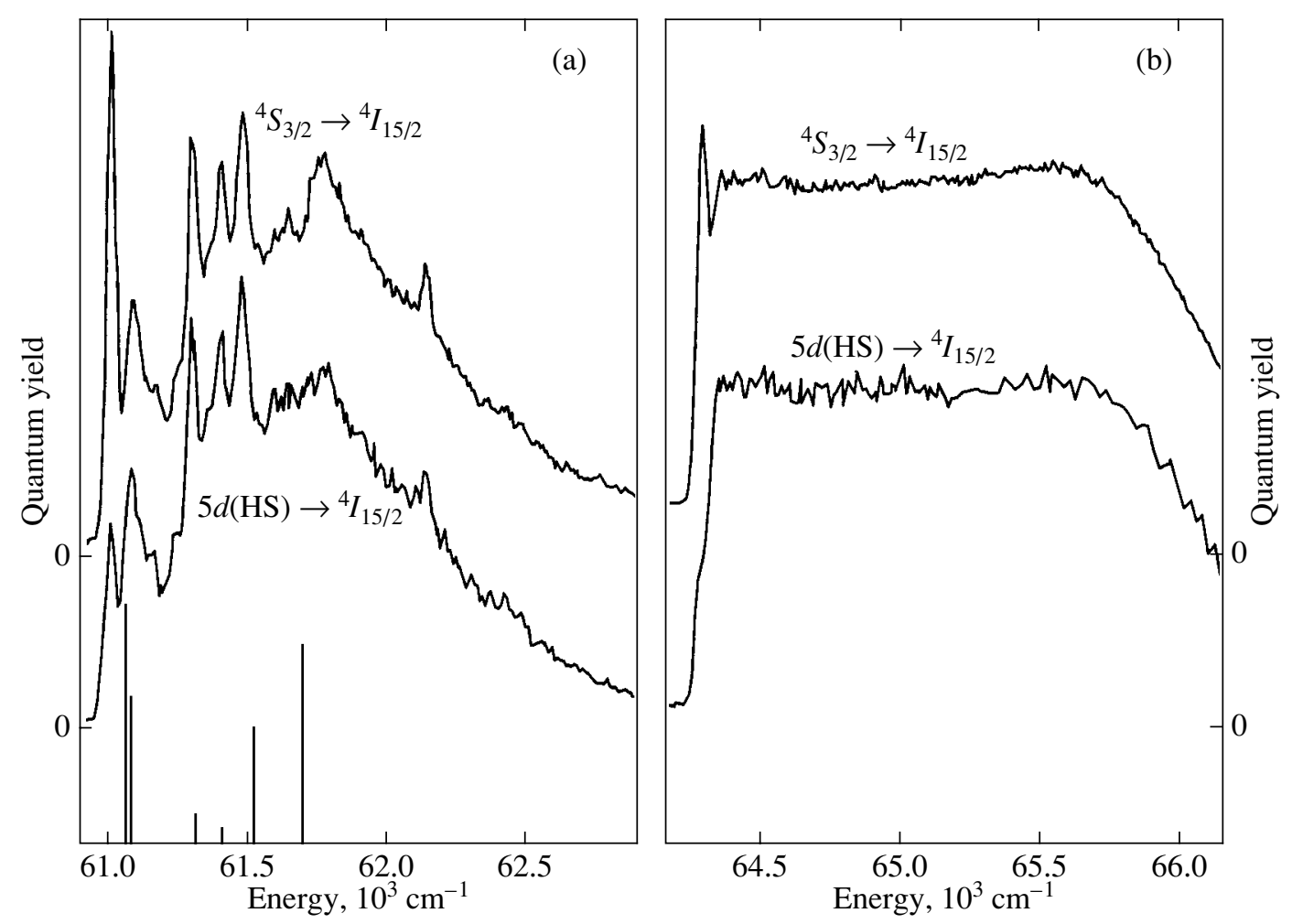

Fig. 2. Excitation spectra of the spin-forbidden $\mathrm{LiYF}_{4}: \mathrm{Er}^{3+}(1 \%) d \rightarrow f$ and ${ }^{4} S_{3 / 2} \longrightarrow{ }^{4} I_{15 / 2}$ emission at the onset of (a) spinforbidden and (b) spin-allowed $f \longrightarrow d$ excitation. $T=9 \mathrm{~K}, \Delta \lambda_{\mathrm{ex}}=0.6 \AA$. 